\title{
The Dog That Didn't Bark: A New Interpretation of Hypsoporphyrin Spectra and the Question of Hypsocorroles
}

\author{
Abhik Ghosh* and Jeanet Conradie*
}

Cite This: J. Phys. Chem. A 2021, 125, 9962-9968

Read Online

ABSTRACT: Nearly a half-century after Gouterman classified the UV-visNIR spectra of porphyrin derivatives as normal, hyper, or hypso, we propose a heretofore unsuspected "mechanism" underlying hypso spectra. Hypsoporphyrins, which exhibit blueshifted optical spectra relative to normal porphyrins (such as $\mathrm{Zn}$ porphyrins), typically involve $\mathrm{d}^{n}$ transition metal ions, where $n>6$. The spectral blueshifts have been traditionally ascribed to elevated porphyrin $e_{g}$ LUMO (lowest unoccupied molecular orbital) energy levels as a result of antibonding interactions with metal $\mathrm{d}_{\pi}$ orbitals. Herein, we have found instead that the blueshifts reflect a lowering of the $a_{2 u}$ HOMO (highest occupied molecular orbital) energy levels. Electronegative metals such as $\mathrm{Pd}$ and $\mathrm{Pt}$ transfer smaller quantities of electron density to the porphyrin nitrogens, compared to a more electropositive metal such as $\mathrm{Zn}$. With large amplitudes at the porphyrin nitrogens, the $\mathrm{a}_{2 \mathrm{u}} \mathrm{HOMOs}$ of $\mathrm{Pd}(\mathrm{II})$ and $\mathrm{Pt}(\mathrm{II})$ porphyrins

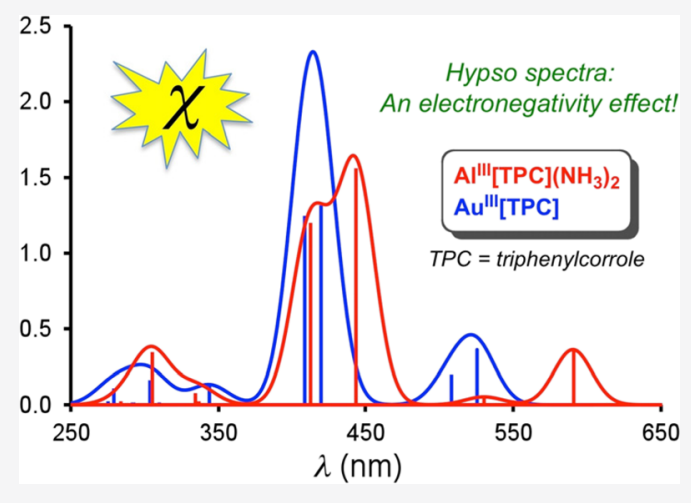
accordingly exhibit lower orbital energies than those of $\mathrm{Zn}$ (II) porphyrins, thus explaining the hypso effect. Hypso spectra are also observed for corroles: compared with six-coordinate $\mathrm{Al}(\mathrm{III})$ corroles, which may be thought of exhibiting normal spectra, $\mathrm{Au}(\mathrm{III})$ corroles, for instance, exhibit blueshifted or hypso spectra.

\section{INTRODUCTION}

The famous four-orbital model, ${ }^{1,2}$ which explained the electronic absorption spectra of simple porphyrins, was devised
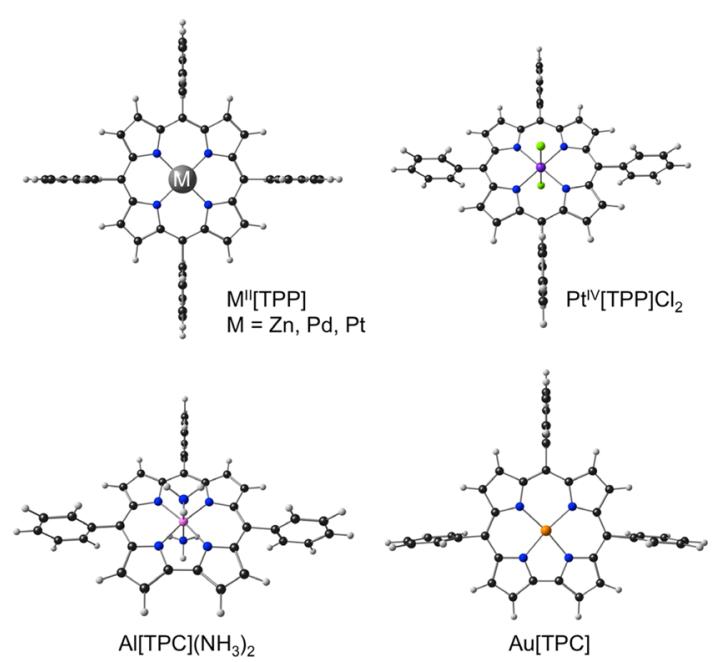

Figure 1. Molecules studied in this work.

by Gouterman in the early 1960s, while he was an Assistant Professor at Harvard. According to this model, the two highest occupied molecular orbitals (HOMOs) $\left(a_{1 u}\right.$ and $a_{2 u}$ under $D_{4 h}$ symmetry) and the two lowest unoccupied molecular orbitals
(LUMOs) $\left(\mathrm{e}_{\mathrm{g}}\right)$ are energetically well-separated from all other occupied and virtual molecular orbitals (MOs). The $Q$ and Soret bands are then explained by transitions between these four MOs, taking configuration interaction into account. Some 15 years later, now on West Coast, he presented an optical taxonomy of porphyrins in a lengthy chapter in Dolphin's multivolume workThe Porphyrins. ${ }^{3}$ He classified porphyrins into three major classes - normal, hypso, and hyper. Normal porphyrins exhibit electronic absorption spectra that can be largely accounted for with the four-orbital model. Hypsoporphyrins exhibit blueshifted spectra, typical examples including $\mathrm{d}^{n}$ metalloporphyrins for $n>6$. In contrast, hyperporphyrins exhibit redshifted optical spectra and/or extra absorption bands above $300 \mathrm{~nm}$. Typical examples include $\mathrm{d}^{n}$ metalloporphyrins with $n<6$, which in turn include many heme proteins and their intermediates and model compounds. Substituents and other structural perturbations can also lead to hyper spectra. ${ }^{4}$

Many, but not all, hypsoporphyrins, especially the noble metal porphyrins, are moderately to strongly phosphorescent. ${ }^{5-7}$ Their long-lived triplet states have been exploited for oxygen

Received: September 24, 2021

Revised: October 21, 2021

Published: November 11, 2021 
Table 1. Comparison of TDDFT and Experimental Absorption Maxima (nm $)^{a}$

\begin{tabular}{|c|c|c|c|c|c|c|c|c|c|c|c|c|c|c|}
\hline \multirow[b]{2}{*}{ compound } & \multicolumn{5}{|c|}{$\mathrm{Q}(\mathrm{nm})$} & \multicolumn{5}{|c|}{ Soret $(\mathrm{nm})$} & \multicolumn{4}{|c|}{ HOMO-LUMO gap (eV) } \\
\hline & OLYP & B3LYP & B3LYP* & $\begin{array}{l}\text { CAMY- } \\
\text { B3LYP }\end{array}$ & Expt & OLYP & B3LYP & B3LYP* & $\begin{array}{l}\text { CAMY- } \\
\text { B3LYP }\end{array}$ & Expt & OLYP & B3LYP & B3LYP* & $\begin{array}{l}\text { CAMY- } \\
\text { B3LYP }\end{array}$ \\
\hline $\mathrm{Zn}[\mathrm{TPP}]$ & 564.3 & 531.2 & 542.0 & 540.4 & 589 & 454.3 & 432.6 & 441.8 & 424.8 & 425 & 1.94 & 2.90 & 2.63 & 4.42 \\
\hline $\mathrm{Pd}[\mathrm{TPP}]$ & 534.9 & 507.0 & 515.6 & 512.7 & 554 & 445.6 & 422.1 & 430.7 & 412.2 & 418 & 2.09 & 3.04 & 2.78 & 4.58 \\
\hline $\mathrm{Pt}[\mathrm{TPP}]$ & 519.7 & 493.7 & 500.2 & 494.5 & 539 & 437.5 & 413.2 & 420.7 & 400.3 & 493 & 2.19 & 3.14 & 2.89 & 4.68 \\
\hline \multirow[t]{2}{*}{$\mathrm{Pt}[\mathrm{TPP}] \mathrm{Cl}_{2}$} & 673.1 & 600.3 & 583.2 & 523.3 & 570 & 445.7 & 423.8 & 431.4 & 414.8 & 421 & 1.81 & 2.87 & 2.72 & 4.50 \\
\hline & 544.0 & 516.3 & 524.5 & 516.5 & & & & & & & & & & \\
\hline \multirow[t]{2}{*}{$\mathrm{Au}[\mathrm{TPC}]$} & 554.4 & 525.9 & 534.6 & 530.3 & 575 & 449.4 & 419.4 & 429.8 & 408.1 & 418 & 1.85 & 2.75 & 2.51 & 4.26 \\
\hline & 537.8 & 508.3 & 516.7 & 507.4 & 560 & 441.2 & 408.4 & 418.5 & 391.8 & & & & & \\
\hline \multirow{2}{*}{$\begin{array}{l}\mathrm{Al}[\mathrm{TPC}]- \\
\left(\mathrm{NH}_{3}\right)_{2}\end{array}$} & 631.7 & 590.7 & 607.6 & 600.7 & 620 & 471.8 & 443.4 & 455.9 & 436.4 & 432 & 1.55 & 2.46 & 2.20 & 3.94 \\
\hline & 570.9 & 530.4 & 544.2 & 528.1 & 582 & 445.4 & 413.0 & 424.3 & 398.0 & 412 & & & & \\
\hline
\end{tabular}

${ }^{a_{T}}$ The experimental data quoted are obtained from refs $40-44$.

(a)

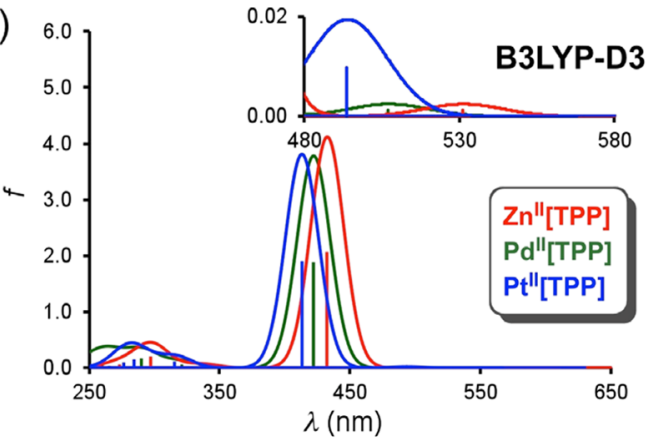

(c)

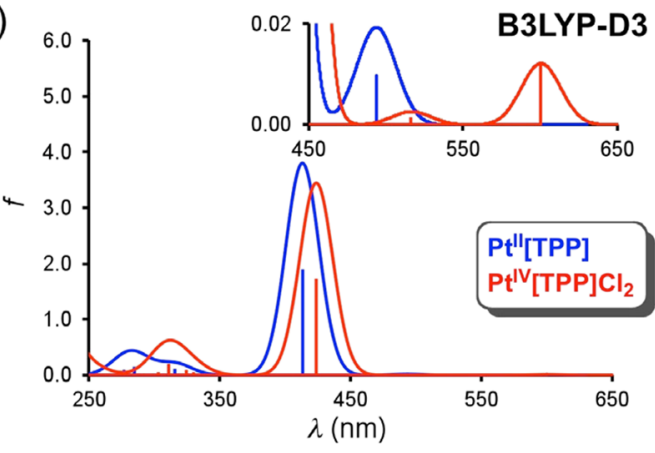

(b)

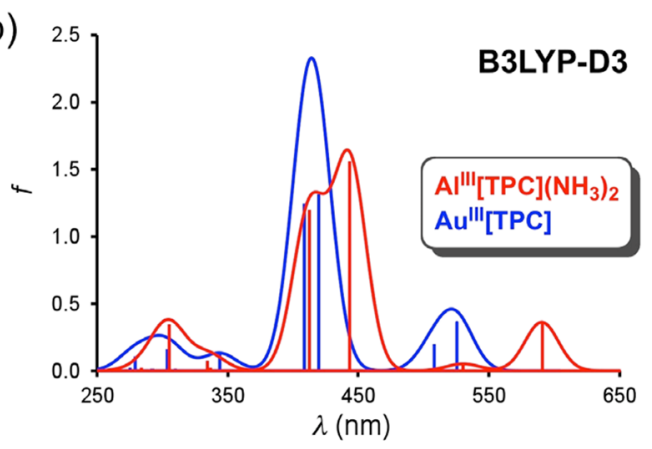

(d)

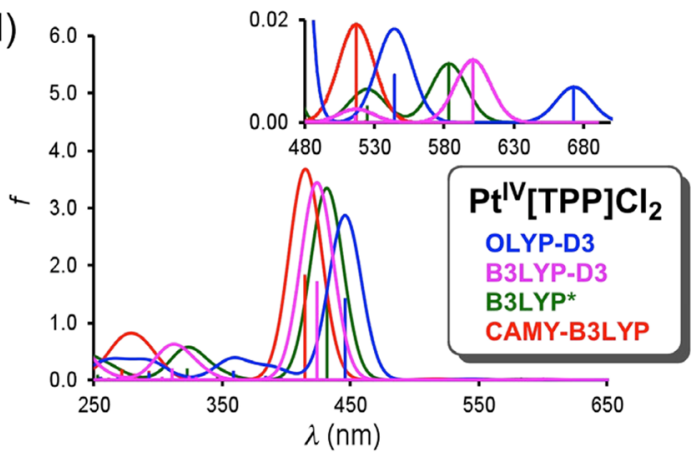

Figure 2. TDDFT (COSMO/dichloromethane) simulated spectra of the metalloporphyrins studied.

sensing and photodynamic therapy. ${ }^{8-12}$ Gouterman and coworkers famously exploited platinum(II) porphyrins to devise pressure-sensitive paints for airplane wings. ${ }^{13-16}$ More recently, $5 \mathrm{~d}$ metallocorroles, ${ }^{17-21}$ including $\mathrm{ReO},{ }^{22-24} \mathrm{OsN},{ }^{25,26} \mathrm{Ir}^{27-29}$ $\mathrm{Pt},{ }^{30,31}$ and $\mathrm{Au}^{20,32-35}$ corroles, have been found to exhibit NIR phosphorescence under ambient conditions, raising the question whether they, or at least some of them, should be described as hypsocorroles.

Remarkably, in spite of their broad importance, few hypso and hyper spectra have been examined by means of modern quantum chemical methods, such as time-dependent density functional theory (TDDFT) calculations, ${ }^{36-38}$ which prompted us to undertake a first such investigation of selected hypsoporphyrin systems. Thus, we examined several $\mathrm{M}^{\mathrm{II}}[\mathrm{TPP}]$ derivatives (where $\mathrm{M}=\mathrm{Zn},{ }^{39,40} \mathrm{Pd}^{41}$ and $\mathrm{Pt}^{41}$ ), $\mathrm{Pt}^{\mathrm{IV}}[\mathrm{TPP}]$ $\mathrm{Cl}_{2}{ }^{42}$ and two corroles, $\mathrm{Al}^{\mathrm{III}}[\mathrm{TPC}]\left(\mathrm{NH}_{3}\right)_{2}{ }^{43}$ and $\mathrm{Au}^{\mathrm{III}}[\mathrm{TPC}]^{34}$ (Figure 1). Of these, only $\mathrm{Pd}^{\mathrm{II}}[\mathrm{TPP}]$ and $\mathrm{Pt}^{\mathrm{II}}[\mathrm{TPP}]$ are clearly hypsoporphyrins, while $\mathrm{Au}[\mathrm{TPC}]$ is a potential hypsocorrole. The other complexes are included for comparison.
The hypso effect has traditionally been explained in terms of $\operatorname{metal}\left(\mathrm{d}_{\pi}\right)$-porphyrin(LUMO) orbital interactions. ${ }^{3}$ By engaging in backbonding interactions with the porphyrin $\mathrm{e}_{\mathrm{g}}$ LUMOs, the $\mathrm{d}_{x z}$ and $\mathrm{d}_{y z}$ orbitals are stabilized. The corresponding antibonding MOs, that is, the LUMOs, the theory goes, are destabilized, which results in an elevated HOMO-LUMO gap, explaining the hypsochromic shifts of the $\mathrm{Q}$ and Soret bands. To our surprise, the present reinvestigation provided no support whatsoever for this long-held picture, suggesting instead an entirely different "mechanism" underlying hypso spectra.

\section{COMPUTATIONAL METHODS}

All calculations were carried out with the $\mathrm{ADF}^{44} 2018$ program with all-electron ZORA-STO-TZ2P basis sets, fine meshes for numerical integration of matrix elements, and adequately tight convergence criteria for both SCF and geometry optimization cycles. Molecular geometries were optimized with $\mathrm{OLYP}^{45,46}$ D3, ${ }^{47}$ with $D_{4 \mathrm{~h}}$ and $C_{2 \mathrm{v}}$ symmetry constraints for the porphyrin and corrole derivatives, respectively. These optimized geo- 
Table 2. B3LYP-D3/STO-TZ2P TDDFT Results, Including Transition Energies $(E)$ and Wavelengths $(l)$, Oscillator Strengths $(f)$, MO Compositions, and Symmetries

\begin{tabular}{|c|c|c|c|c|c|c|c|c|}
\hline \multirow[b]{2}{*}{ molecule } & \multirow[b]{2}{*}{ peak } & \multirow[b]{2}{*}{$E(\mathrm{eV})$} & \multirow[b]{2}{*}{$\lambda(\mathrm{nm})$} & \multirow[b]{2}{*}{$f$} & \multicolumn{2}{|c|}{ MO composition } & \multirow[b]{2}{*}{ weight (\%) } & \multirow[b]{2}{*}{ state symmetry } \\
\hline & & & & & from & to & & \\
\hline \multirow[t]{3}{*}{$\mathrm{Zn}[\mathrm{TPP}]$} & Q & 2.33 & 531.2 & 0.001 & HOMO & LUMO & 55 & $\mathrm{E}_{\mathrm{u}}$ \\
\hline & & & & & HOMO - 1 & LUMO & 45 & $\mathrm{E}_{\mathrm{u}}$ \\
\hline & Soret & 2.87 & 432.6 & 2.061 & HOMO - 1 & LUMO & 54 & $\mathrm{E}_{\mathrm{u}}$ \\
\hline \multirow[t]{4}{*}{$\mathrm{Pd}[\mathrm{TPP}]$} & Q & 2.45 & 507.0 & 0.001 & HOMO - 1 & LUMO & 50 & $\mathrm{E}_{\mathrm{u}}$ \\
\hline & & & & & HOMO & LUMO & 49 & $\mathrm{E}_{\mathrm{u}}$ \\
\hline & Soret & 2.94 & 422.1 & 1.891 & HOMO & LUMO & 49 & $\mathrm{E}_{\mathrm{u}}$ \\
\hline & & & & & HOMO - 1 & LUMO & 49 & $\mathrm{E}_{\mathrm{u}}$ \\
\hline \multirow[t]{4}{*}{$\mathrm{Pt}[\mathrm{TPP}]$} & Q & 2.51 & 493.7 & 0.010 & HOMO - 1 & LUMO & 55 & $\mathrm{E}_{\mathrm{u}}$ \\
\hline & & & & & HOMO & LUMO & 44 & $\mathrm{E}_{\mathrm{u}}$ \\
\hline & Soret & 3.00 & 413.2 & 1.906 & HOMO & LUMO & 54 & $\mathrm{E}_{\mathrm{u}}$ \\
\hline & & & & & HOMO - 1 & LUMO & 44 & $\mathrm{E}_{\mathrm{u}}$ \\
\hline \multirow[t]{5}{*}{$\mathrm{Pt}[\mathrm{TPP}] \mathrm{Cl}_{2}$} & Q & 2.07 & 600.3 & 0.012 & HOMO & LUMO & 100 & $\mathrm{~A}_{2 \mathrm{u}}$ \\
\hline & & 2.40 & 516.3 & 0.001 & HOMO & LUMO + 1 & 55 & $\mathrm{E}_{\mathrm{u}}$ \\
\hline & & & & & HOMO - 1 & $\mathrm{LUMO}+1$ & 44 & $\mathrm{E}_{\mathrm{u}}$ \\
\hline & Soret & 2.93 & 423.8 & 1.722 & HOMO - 1 & LUMO + 1 & 54 & $\mathrm{E}_{\mathrm{u}}$ \\
\hline & & & & & HOMO & LUMO + 1 & 42 & $\mathrm{E}_{\mathrm{u}}$ \\
\hline \multirow[t]{8}{*}{$\mathrm{Au}[\mathrm{TPC}]$} & Q & 2.36 & 525.9 & 0.362 & HOMO & LUMO & 88 & $\mathrm{~B}_{2}$ \\
\hline & & & & & HOMO - 1 & $\mathrm{LUMO}+1$ & 11 & $\mathrm{~B}_{2}$ \\
\hline & & 2.44 & 508.3 & 0.204 & HOMO - 1 & LUMO & 81 & $A_{1}$ \\
\hline & & & & & HOMO & $\mathrm{LUMO}+1$ & 18 & $\mathrm{~A}_{1}$ \\
\hline & Soret & 2.96 & 419.4 & 1.312 & HOMO & LUMO + 1 & 80 & $\mathrm{~A}_{1}$ \\
\hline & & & & & HOMO - 1 & LUMO & 17 & $A_{1}$ \\
\hline & & 3.04 & 408.4 & 1.248 & HOMO - 1 & $\mathrm{LUMO}+1$ & 87 & $\mathrm{~B}_{2}$ \\
\hline & & & & & HOMO & LUMO & 11 & $\mathrm{~B}_{2}$ \\
\hline \multirow[t]{8}{*}{$\mathrm{Al}[\mathrm{TPC}]\left(\mathrm{NH}_{3}\right)_{2}$} & Q & 2.10 & 590.7 & 0.362 & HOMO & LUMO & 91 & $\mathrm{~B}_{2}$ \\
\hline & & & & & HOMO - 1 & $\mathrm{LUMO}+1$ & 8 & $\mathrm{~B}_{2}$ \\
\hline & & 2.34 & 530.4 & 0.052 & HOMO - 1 & LUMO & 60 & $A_{1}$ \\
\hline & & & & & HOMO & $\mathrm{LUMO}+1$ & 39 & $A_{1}$ \\
\hline & Soret & 2.80 & 443.4 & 1.561 & HOMO & $\mathrm{LUMO}+1$ & 59 & $A_{1}$ \\
\hline & & & & & HOMO - 1 & LUMO & 39 & $A_{1}$ \\
\hline & & 3.00 & 413.0 & 1.204 & HOMO - 1 & $\mathrm{LUMO}+1$ & 91 & $\mathrm{~B}_{2}$ \\
\hline & & & & & HOMO & LUMO & 7 & $\mathrm{~B}_{2}$ \\
\hline
\end{tabular}

metries were then used for TDDFT calculations with the OLYPD3, B3LYP* (15\% exact exchange), and CAMY-B3LYP ${ }^{48-50}$ functionals. B3LYP ${ }^{51,52}$-D3-optimized geometries were used for the TDDFT calculations with the B3LYP functional. The $\mathrm{COSMO}^{53}$ solvation model (with dichloromethane as the solvent) was used throughout.

\section{RESULTS AND DISCUSSION}

3.1. Theoretical Model. We began by examining to what extent TDDFT calculations reproduce known trends in relative positions of the absorption maxima of the compounds studied. As mentioned above, four exchange-correlation functionals were examined-OLYP-D3, B3LYP-D3, B3LYP*, and CAMYB3LYP-with solvation (dichloromethane) taken into account with the COSMO model. Table 1 lists calculated and experimental absorption maxima and calculated HOMOLUMO gaps, while Figure 2 presents selected simulated spectra, mostly from B3LYP-D3 calculations. It is immediately obvious that all the exchange-correlation functionals do a qualitatively good job of reproducing key trends in experimental absorption maxima. Thus, both the $\mathrm{Q}$ and Soret bands of $\mathrm{Pd}^{\mathrm{II}}[\mathrm{TPP}]$ and $\mathrm{Pt}^{\mathrm{II}}$ [TPP] are hypsochromically shifted relative to those of $\mathrm{Zn}^{\mathrm{II}}[\mathrm{TPP}]$, with larger blueshifts for $\mathrm{Pt}$, just as experimentally observed. $^{39-41}$ The calculations also predict a substantial spectral blueshift for $\mathrm{Au}^{\mathrm{III}}[\mathrm{TPC}]$ relative to $\mathrm{Al}[\mathrm{TPC}]\left(\mathrm{NH}_{3}\right)_{2}$, mirroring a qualitatively similar blueshift for $\mathrm{Au}^{\mathrm{III}}[\mathrm{TPFPC}]$ relative to $\mathrm{Al}^{\mathrm{III}}[\mathrm{TPFPC}](\mathrm{py})_{2} \cdot{ }^{33,43}$ Finally, the calculations predict a spectral redshift for $\mathrm{Pt}^{\mathrm{V}}[\mathrm{TPP}] \mathrm{Cl}_{2}$ relative to $\mathrm{Pt}^{\mathrm{II}}[\mathrm{TPP}]$, again in qualitative accord with experimental results. ${ }^{41,42}$

Interestingly, the lowest-energy $\mathrm{Q}$ band of $\mathrm{Pt}^{\mathrm{IV}}[\mathrm{TPP}] \mathrm{Cl}_{2}$ appears to pose a peculiar challenge for some of the functionals. Thus, the calculated lowest-energy transition for this compound (experimental value:570 $\mathrm{nm}^{42}$ ) is not a true $Q$ band but a $\operatorname{HOMO}\left(a_{2 \mathrm{u}}\right) \rightarrow \operatorname{LUMO}\left(\mathrm{a}_{1 \mathrm{~g}}\right)$ transition, where the $\mathrm{a}_{1 \mathrm{~g}}$ LUMO corresponds to the empty $\mathrm{d}_{\mathrm{z} 2}$ orbital of the $\mathrm{Pt}(\mathrm{IV})$ center. Table 1 shows that while OLYP unduly redshifts this feature, CAMYB3LYP results in an undue blueshift, whereas B3LYP-D3 and B3LYP* perform just about right.

3.2. MO Analysis. A first step toward understanding the hypsoporphyrin effect is to examine the MO composition of the various calculated spectral features. This information is provided in Table 2 for the B3LYP-D3 functional, while key MOs are depicted in Figure 3 for one of the complexes, $\mathrm{Pt}^{\mathrm{II}}[\mathrm{TPP}]$. To our considerable surprise, we found that the four frontier MOs of all the complexes examined, except $\mathrm{Pt}{ }^{\mathrm{V}}[\mathrm{TPP}] \mathrm{Cl}_{2}$, correspond to classic Gouterman MOs, with little or no metal d character. Even for the two corrole derivatives, the four frontier MOs for $\mathrm{Au}^{\mathrm{III}}[\mathrm{TPC}]$ (Figure 4) and $\mathrm{Al}^{\mathrm{III}}[\mathrm{TPC}]\left(\mathrm{NH}_{3}\right)_{2}$ look essentially identical. This finding, reminiscent of the Sherlock Holmes story (Silver Blaze) about "the dog that didn't bark in the night-time", 

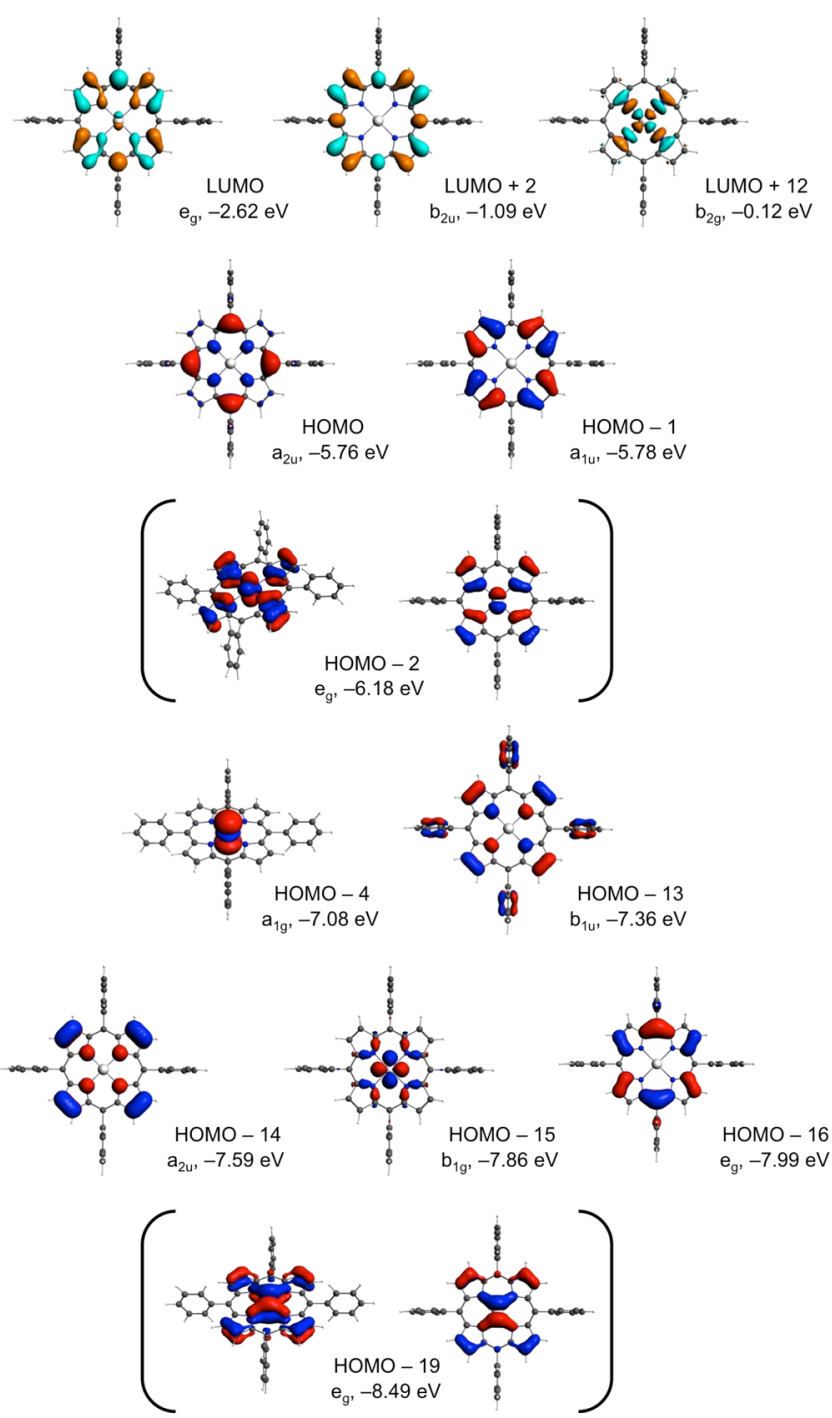

Figure 3. Selected B3LYP-D3 frontier MOs of $\mathrm{Pt}^{\mathrm{II}}[\mathrm{TPP}]$.

flies in the face of-and indeed invalidates-the conventional explanation for the hypsoporphyrin effect, namely, that a $\pi$ antibonding interaction with the metal $\mathrm{d}_{\pi}$ orbitals is responsible for an elevation of the orbital energies of the $e_{g}$ LUMOs.

A comparative study of the frontier MO energy levels (Figures 5 and 6) came to our rescue. While the LUMO energy levels were found to be almost identical across all the porphyrin (or corrole) derivatives studied, the hypsoporphyrins examined exhibit lower orbital energies for the $a_{2 u}$ HOMOs (or for the topologically similar $b_{1}$ HOMOs of corroles). This, then, appears to be the new explanation for the hypsoporphyrin effect.

3.3. Molecular Charge Distributions. The question as to why hypsoporphyrins such as $\mathrm{Pd}^{\mathrm{II}}[\mathrm{TPP}]$ and $\mathrm{Pt}^{\mathrm{II}}[\mathrm{TPP}]$, as well as hypsocorroles such as $\mathrm{Au}^{\mathrm{III}}[\mathrm{TPC}]$, should exhibit lower " $\mathrm{a}_{2 \mathrm{u}}$ " energy levels is a somewhat subtle one, because, as mentioned, there is little difference in the shape of these orbitals relative to those of the normal porphyrin $\mathrm{Zn}{ }^{\mathrm{II}}[\mathrm{TPP}]$ [and the normal corrole $\left.\mathrm{Al}^{\mathrm{III}}[\mathrm{TPC}]\left(\mathrm{NH}_{3}\right)_{2}\right]$. An examination of the atomic Mulliken and Hirschfeld charges, as well as of the nitrogen 1s orbital energies (Table 3), suggests a plausible explanation. Hypsoporphyrins appear to involve less electropositive metals that transfer less electron density to the porphyrin/corrole ligands as a whole and specifically to the macrocycle nitrogens.
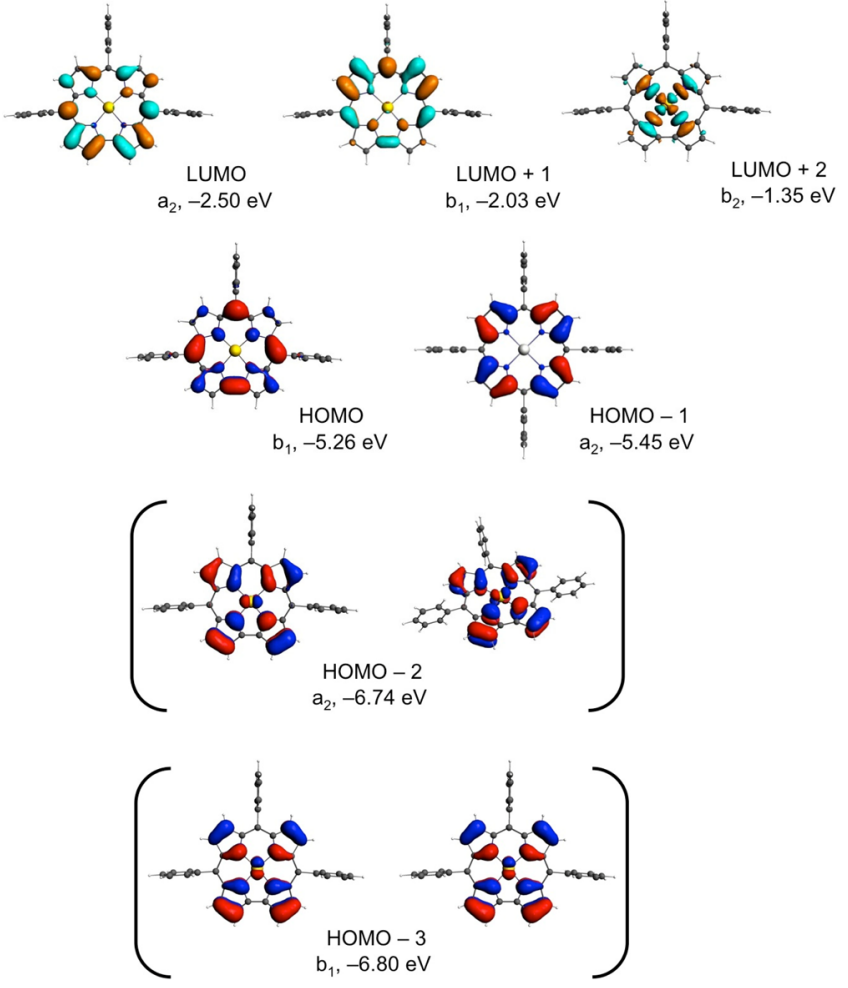

Figure 4. Selected B3LYP-D3 frontier MOs of $\mathrm{Au}^{\mathrm{III}}[\mathrm{TPC}]$.

Thus, both the macrocyclic ligands as a whole and their central nitrogens carry less negative Hirschfeld charges in the case of the hypsoporphyrins, relative to the normal porphyrin $\mathrm{Zn}^{\mathrm{II}}[\mathrm{TPP}]$. As a result, the nitrogen 1 s orbital energies are also relatively more negative, which would translate to higher XPS ionization potentials, for the hypsoporphyrins. Given that the $\mathrm{a}_{2 \mathrm{u}} \mathrm{HOMO}$ has large amplitudes on the macrocycle nitrogens, it follows that hypsoporphyrins should also exhibit lower $\mathrm{a}_{2 \mathrm{u}}$ orbital energies, which accounts for the hypsoporphyrin effect.

The above argument might suggest that a $\mathrm{Pt}(\mathrm{IV})$ porphyrin would exhibit a stronger hypsochromic shift than a $\mathrm{Pt}(\mathrm{II})$ porphyrin. As shown in Table 1, the opposite is observed. A recent, combined X-ray absorption spectroscopy and density functional theory (DFT) study has shown that a $\mathrm{Pt}(\mathrm{IV}$ ) porphyrin entails substantial oxidation of the porphyrin ligand as a whole. ${ }^{54}$ That systemic oxidation results in a lowering of not only the $a_{2 u}$ HOMO, but also an even greater lowering of the $\mathrm{e}_{\mathrm{g}} \mathrm{LUMOs}$, which explains the lack of a hypsoporphyrin spectrum for $\mathrm{Pt}^{\mathrm{IV}}[\mathrm{TPP}] \mathrm{Cl}_{2}$.

\section{CONCLUSIONS}

DFT and TDDFT calculations indicate that the hypsoporphyrin effect (blueshifted $Q$ and Soret bands) does not result from elevated porphyrin LUMO $\left(\mathrm{e}_{\mathrm{g}}\right)$ energy levels as a result of antibonding interactions with metal $\mathrm{d}_{\pi}$ orbitals. Instead the observed blueshifts reflect a lowering of the $a_{2 u}$ HOMO energy level. Electronegative metals such as $\mathrm{Pd}$ and $\mathrm{Pt}$ transfer smaller quantities of electron density to the porphyrin nitrogens, compared to a more electropositive metal such as $\mathrm{Zn}$. As a result, the nitrogens in $\mathrm{Pd}$ and $\mathrm{Pt}$ porphyrins exhibit higher electrostatic potentials, more negative $\mathrm{N} 1$ s orbital energies, and higher $\mathrm{N} 1 \mathrm{~s}$ ionization potentials. With large amplitudes at the porphyrin nitrogens, the $\mathrm{a}_{2 \mathrm{u}}$ HOMOs of $\mathrm{Pd}(\mathrm{II})$ and $\mathrm{Pt}(\mathrm{II})$ porphyrins also exhibit lower orbital energies (mirroring the behavior of the $\mathrm{N} 1 \mathrm{~s}$ 
Table 3. Selected Mulliken and Hirschfeld Charges and N 1s Orbital Energies (eV) for the Compounds Studied

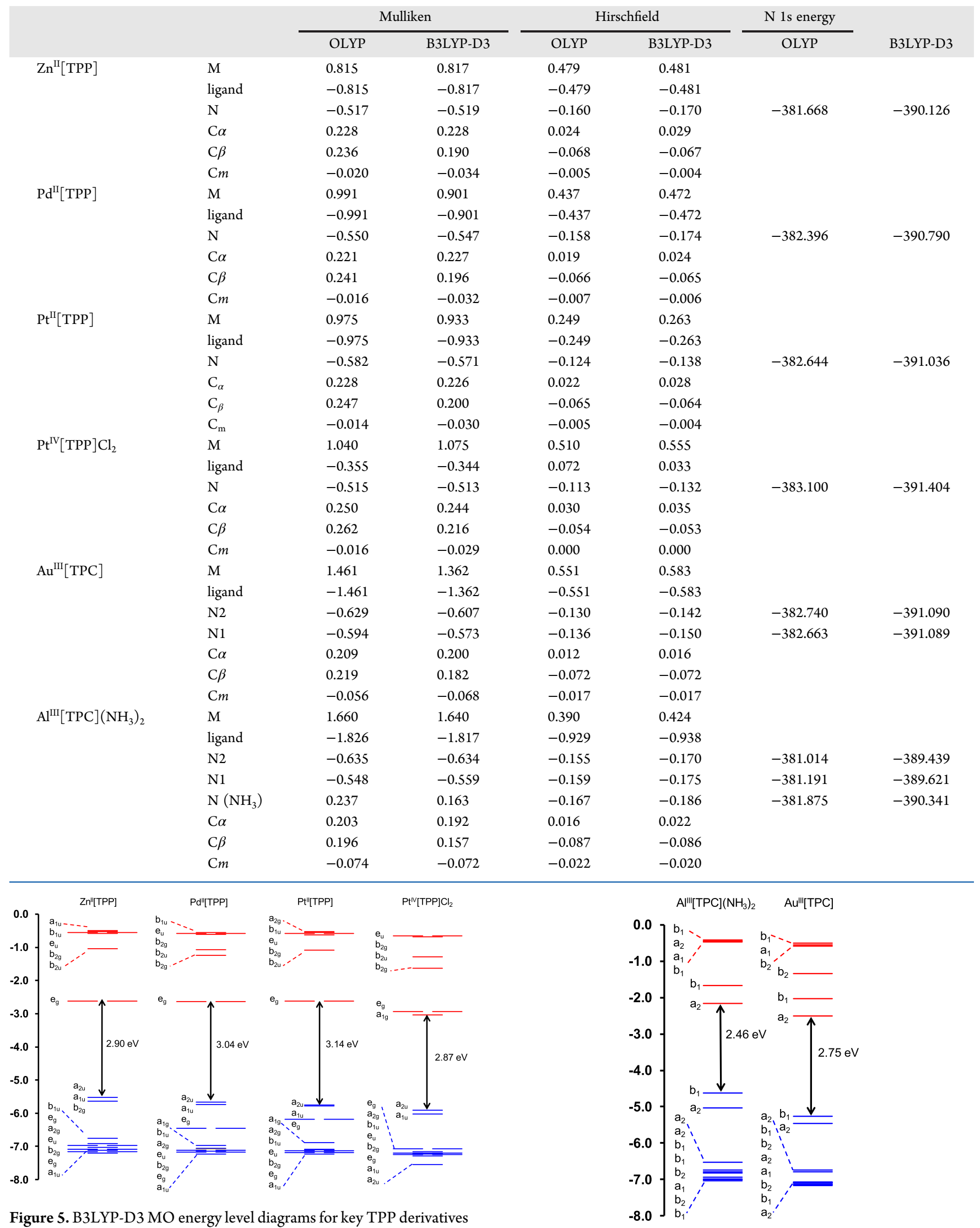
studied.

Figure 6. B3LYP-D3 MO energy level diagrams for key TPC derivatives. 
orbitals) than $\mathrm{Zn}(\mathrm{II})$ porphyrins, thus explaining the hypsoporphyrin spectra.

The hypsoporphyrin concept also appears to extend to corroles. With blueshifted spectral features relative to sixcoordinate $\mathrm{Al}(\mathrm{III})$ corroles, $\mathrm{Au}(\mathrm{III})$ corroles appear to be justifiably described as hypsocorroles. It may be recalled that examples hypercorroles, likewise, have also been documented in the literature. 55

\section{ASSOCIATED CONTENT}

\section{SI Supporting Information}

The Supporting Information is available free of charge at https://pubs.acs.org/doi/10.1021/acs.jpca.1c08425.

Optimized Cartesian coordinates (PDF)

\section{AUTHOR INFORMATION}

\section{Corresponding Authors}

Abhik Ghosh - Department of Chemistry, UiT-The Arctic University of Norway, Tromsø N-9037, Norway; 가이.orcid/0000-0003-1161-6364; Email: abhik.ghosh@ uit.no

Jeanet Conradie - Department of Chemistry, UiT-The Arctic University of Norway, Tromsø N-9037, Norway; Department of Chemistry, University of the Free State, Bloemfontein 9300, Republic of South Africa; (1) orcid.org/0000-0002-81206830; Email: conradj@ufs.ac.za

Complete contact information is available at: https://pubs.acs.org/10.1021/acs.jpca.1c08425

\section{Notes}

The authors declare no competing financial interest.

\section{ACKNOWLEDGMENTS}

This work was supported by grant no. 262229 and of the Research Council of Norway (AG) and grant nos. 129270 and 132504 of South African National Research Foundation.

\section{REFERENCES}

(1) Gouterman, M.; Wagniére, G. H.; Snyder, L. C. Spectra of Porphyrins. Part II. Four-Orbital Model. J. Mol. Spectrosc. 1963, 11, $108-127$.

(2) For a recent biography of Martin Gouterman, see Ghosh, A. An Exemplary Gay Scientist and Mentor: Martin Gouterman (19312020). Angew. Chem., Int. Ed. 2021, 60, 9760-9770.

(3) Gouterman, M. Optical Spectra and Electronic Structure of Porphyrins and Related Rings. In The Porphyrins; Dolphin, D., Ed.; Academic Press: New York, 1978; Vol. III, Part A, pp 1-165.

(4) Vitasovic, M.; Gouterman, M.; Linschitz, H. J. Porphyrins Pthalocyanines 2001, 05, 191-197.

(5) Buchler, J. W.; Dreher, C.; Künzel, F. M. Synthesis and coordination chemistry of noble metal porphyrins. Struct. Bonding 1995, 84, 1-69.

(6) Antipas, A.; Dolphin, D.; Gouterman, M.; Johnson, E. C. Porphyrins. 38.1 Redox Potentials, Charge Transfer Transitions, and Emission of Copper, Silver, and Gold Complexes. J. Am. Chem. Soc. 1978, 100, 7705-7709.

(7) Papkovsky, D. B.; O’Riordan, T. C. Emerging Applications of Phosphorescent Metalloporphyrins. J. Fluoresc. 2005, 15, 569-584.

(8) Kwong, R. C.; Sibley, S.; Dubovoy, T.; Baldo, M.; Forrest, S. R.; Thompson, M. E. Efficient, Saturated Red Organic Light Emitting Devices Based on Phosphorescent Platinum(II) Porphyrins. Chem. Mater. 1999, 11, 3709-3713.

(9) Sommer, J. R.; Shelton, A. H.; Parthasarathy, A.; Ghiviriga, I.; Reynolds, J. R.; Schanze, K. S. Photophysical Properties of Near-
Infrared Phosphorescent $\pi$-Extended Platinum Porphyrins. Chem. Mater. 2011, 23, 5296-5304.

(10) Briñas, R. P.; Troxler, T.; Hochstrasser, R. M.; Vinogradov, S. A. Phosphorescent Oxygen Sensor with Dendritic Protection and TwoPhoton Absorbing Antenna. J. Am. Chem. Soc. 2005, 127, 1185111862.

(11) Wu, F.; Yue, L.; Su, H.; Wang, K.; Yang, L.; Zhu, X. Carbon Dots (a) Platinum Porphyrin Composite as Theranostic Nanoagent for Efficient Photodynamic Cancer Therapy. Nanoscale Res. Lett. 2018, 13, 357.

(12) Deng, J.; Li, H.; Yang, M.; Wu, F. Palladium porphyrin complexes for photodynamic cancer therapy: effect of porphyrin units and metal. Photochem. Photobiol. Sci. 2020, 19, 905-912.

(13) Kavandi, J.; Callis, J.; Gouterman, M.; Khalil, G.; Wright, D.; Green, E. Luminescent barometry in wind tunnels. Rev. Sci. Instrum. 1990, 61, 3340-3347.

(14) Khalil, G. E.; Costin, C.; Crafton, J.; Jones, G.; Grenoble, S.; Gouterman, M.; Callis, J. B.; Dalton, L. R. Dual-luminophor pressuresensitive paint: I. Ratio of reference to sensor giving a small temperature dependency. Sens. Actuators, B 2004, 97, 13-21.

(15) Zelelow, B.; Khalil, G. E.; Phelan, G.; Carlson, B.; Gouterman, M.; Callis, J. B.; Dalton, L. R. Dual luminophor pressure sensitive paint: II. Lifetime based measurement of pressure and temperature. Sens. Actuators, B 2003, 96, 304-314.

(16) Gouterman, M. Oxygen Quenching of Luminescence of Pressure Sensitive Paint for Wind Tunnel Research. J. Chem. Educ. 1997, 74, 697-702.

(17) Ghosh, A. Electronic Structure of Corrole Derivatives: Insights from Molecular Structures, Spectroscopy, Electrochemistry, and Quantum Chemical Calculations. Chem. Rev. 2017, 117, 3798-3881.

(18) Teo, R. D.; Hwang, J. Y.; Termini, J.; Gross, Z.; Gray, H. B. Fighting Cancer with Corroles. Chem. Rev. 2017, 117, 2711-2729.

(19) Nardis, S.; Mandoj, F.; Stefanelli, M.; Paolesse, R. Metal complexes of corrole. Coord. Chem. Rev. 2019, 388, 360-405.

(20) Lemon, C. M.; Powers, D. C.; Brothers, P. J.; Nocera, D. G. Gold Corroles as Near-IR Phosphors for Oxygen Sensing. Inorg. Chem. 2017, 56, 10991-10997.

(21) Alemayehu, A. B.; Thomas, K. E.; Einrem, R. F.; Ghosh, A. The Story of 5d Metallocorroles: From Metal-Ligand Misfits to New Building Blocks for Cancer Phototherapeutics. Acc. Chem. Res. 2021, 54, 3095-3107.

(22) Einrem, R. F.; Gagnon, K. J.; Alemayehu, A. B.; Ghosh, A. MetalLigand Misfits: Facile Access to Rhenium-Oxo Corroles by Oxidative Metalation. Chem. - Eur. J. 2016, 22, 517-520.

(23) Borisov, S. M.; Einrem, R. F.; Alemayehu, A. B.; Ghosh, A. Ambient-temperature near-IR phosphorescence and potential applications of rhenium-oxo corroles. Photochem. Photobiol. Sci. 2019, 18, $1166-1170$.

(24) Einrem, R. F.; Alemayehu, A. B.; Borisov, S. M.; Ghosh, A.; Gederaas, O. A. Amphiphilic Rhenium-Oxo Corroles as a New Class of Sensitizers for Photodynamic Therapy. ACS Omega 2020, 5, 1059610601.

(25) Alemayehu, A. B.; Gagnon, K. J.; Terner, J.; Ghosh, A. Oxidative Metalation as a Route to Size-Mismatched Macrocyclic Complexes: Osmium Corroles. Angew. Chem., Int. Ed. 2014, 53, 14411-14414.

(26) Borisov, S. M.; Alemayehu, A.; Ghosh, A. Osmium-Nitrido Corroles as NIR Indicators for Oxygen Sensors and Triplet Sensitizers for Organic Upconversion and Singlet Oxygen Generation. J. Mater. Chem. C 2016, 4, 5822-5828.

(27) Palmer, J. H.; Durrell, A. C.; Gross, Z.; Winkler, J. R.; Gray, H. B. Near-IR Phosphorescence of Iridium(III) Corroles at Ambient Temperature. J. Am. Chem. Soc. 2010, 132, 9230-9231.

(28) Sinha, W.; Ravotto, L.; Ceroni, P.; Kar, S. NIR-Emissive Iridium(III) Corrole Complexes as Efficient Singlet Oxygen Sensitizers. Dalton Trans. 2015, 44, 17767-17773.

(29) Thomassen, I. K.; McCormick-McPherson, L. J.; Borisov, S. M.; Ghosh, A. Iridium Corroles Exhibit Weak Near-Infrared Phosphorescence but Efficiently Sensitize Singlet Oxygen Formation. Sci. Rep. 2020, 10, 7551. 
(30) Alemayehu, A. B.; Vazquez-Lima, H.; Beavers, C. M.; Gagnon, K. J.; Bendix, J.; Ghosh, A. Platinum Corroles. Chem. Commun. 2014, 50, 11093-11096.

(31) Alemayehu, A. B.; McCormick, L. J.; Gagnon, K. J.; Borisov, S. M.; Ghosh, A. Stable Platinum(IV) Corroles: Synthesis, Molecular Structure, and Room-Temperature Near-IR Phosphorescence. ACS Omega 2018, 3, 9360-9368.

(32) Alemayehu, A. B.; Ghosh, A. Gold Corroles. J. Porphyrins Phthalocyanines 2011, 15, 106-110.

(33) Rabinovitch, E.; Goldberg, I.; Gross, Z. Gold(I) and Gold(III) Corroles. Chem. - Eur. J. 2011, 17, 12294-12301.

(34) Thomas, K. E.; Alemayehu, A. B.; Conradie, J.; Beavers, C.; Ghosh, A. Synthesis and Molecular Structure of Gold Triarylcorroles. Inorg. Chem. 2011, 50, 12844-12851.

(35) Alemayehu, A. B.; Jae Day, N. U.; Mani, T.; Rudine, A. B.; Thomas, K. E.; Gederaas, O. A.; Vinogradov, S. A.; Wamser, C. C.; Ghosh, A. Gold Tris(carboxyphenyl)corroles as Multifunctional Materials: Room Temperature Near-IR Phosphorescence and Applications to Photodynamic Therapy and Dye-Sensitized Solar Cells. ACS Appl. Mater. Interfaces 2016, 8, 18935-18942.

(36) For a comprehensive introduction to TDDFT, see: Ullrich, C. A. Time-Dependent Density-Functional Theory: Concepts and Applications; Oxford University Press: Oxford, U. K., 2011.

(37) Alemayehu, A. B.; Conradie, J.; Ghosh, A. A First TDDFT Study of Metallocorrole Electronic Spectra: Copper meso-Triarylcorroles Exhibit Hyper Spectra. Eur. J. Inorg. Chem. 2011, 12, 1857-1864.

(38) Conradie, J.; Wamser, C. C.; Ghosh, A. Understanding Hyperporphyrin Spectra: TDDFT Calculations on Diprotonated Tetrakis( $p$-aminophenyl)porphyrin. J. Phys. Chem. A 2021, previous article in this issue: DOI: 10.1021/acs.jpca.1c06621.

(39) Dorough, G. D.; Miller, J. R.; Huennekens, F. M. Spectra of the Metallo-derivatives of $\alpha, \beta, \gamma, \delta$-Tetraphenylporphine. J. Am. Chem. Soc. 1951, 73, 4315-4320.

(40) Edwards, L.; Dolphin, D. H.; Gouterman, M.; Adler, A. D. Porphyrins XVII. Vapor absorption spectra and redox reactions: Tetraphenylporphins and porphin. J. Mol. Spectrosc. 1971, 38, 16-32. (41) Thomas, D. W.; Martell, A. E. Visible and ultraviolet absorption spectra of metal chelates of para-substituted tetraphenylporphines. Arch. Biochem. Biophys. 1958, 76, 286-294.

(42) Mink, L. M.; Neitzel, M. L.; Bellomy, L. M.; Falvo, R. E.; Boggess, R. K.; Trainum, B. T.; Yeaman, P. Platinum(II) and platinum(IV) porphyrin complexes: synthesis, characterization, and electrochemistry. Polyhedron 1997, 16, 2809-2817.

(43) The calculated data on $\mathrm{Al}^{\mathrm{III}}[\mathrm{TPC}]\left(\mathrm{NH}_{3}\right)_{2}$ have been compared to experimental data on $\mathrm{Al}^{\mathrm{III}}[\mathrm{TPFPC}](\mathrm{py})_{2}$ Mahammed, A.; Gross, Z. Aluminum Corrolin, A Novel Chlorophyll Analogue. J. Inorg. Biochem. 2002, 88, 305-309.

(44) Velde, G. T.; Bickelhaupt, F. M.; Baerends, E. J.; Guerra, C. F.; van Gisbergen, S. J. A.; Snijders, J. G.; Ziegler, T. Chemistry with ADF. J. Comput. Chem. 2001, 22, 931-967.

(45) Handy, N. C.; Cohen, A. J. Left-right correlation energy. Mol. Phys. 2001, 99, 403-412.

(46) Lee, C.; Yang, W.; Parr, R. G. Development of the Colle-Salvetti correlation-energy formula into a functional of the electron density. Phys. Rev. B 1988, 37, 785-789.

(47) Grimme, S.; Anthony, J.; Ehrlich, S.; Krieg, H. A Consistent and Accurate $A b$ Initio Parametrization of Density Functional Dispersion Correction (DFT-D) for the 94 Elements H-Pu. J. Chem. Phys. 2010, 132, 154104.

(48) Seth, M.; Ziegler, T. Range-Separated Exchange Functionals with Slater-Type Functions. J. Chem. Theory Comput. 2012, 8, 901-907.

(49) Note that CAMY-B3LYP is the Yukawa form of CAM-B3LYP ${ }^{51}$ with $a=0.19$ and $b=0.46$ (and $g=0.34$ ) but with the Yukawa potential as the switching function, as opposed to the Coulomb potential attenuated by the complementary error function.

(50) Yanai, T.; Tew, D. P.; Handy, N. C. A new hybrid exchangecorrelation functional using the Coulomb-attenuating method (CAMB3LYP). Chem. Phys. Lett. 2004, 393, 51-57.
(51) Becke, A. D. Density-functional exchange-energy approximation with correct asymptotic behaviour. Phys. Rev. A 1988, 38, 3098-3100.

(52) Miehlich, B.; Savin, A.; Stoll, H.; Preuss, H. Results Obtained with the Correlation Energy Density Functionals of Becke and Lee, Yang and Parr. Chem. Phys. Lett. 1989, 157, 200-206.

(53) Klamt, A.; Schürmann, G. COSMO: A New Approach to Dielectric Screening in Solvents with Explicit Expressions for the Screening Energy and Its Gradient. J. Chem. Soc., Perkin Trans. 2 1993, 799-805.

(54) Matson, B.; Thomas, K. E.; Alemayehu, A. B.; Ghosh, A.; Sarangi, R. X-ray absorption spectroscopy of exemplary platinum porphyrin and corrole derivatives: metal- versus ligand-centered oxidation. RSC Adv. 2021, 11, 32269-32274. Correction. RSC Adv. 2021, 11, 33300-33300.

(55) Thomassen, I. K.; Ghosh, A. Protonation-Induced Hyperporphyrin Spectra of meso-Aminophenylcorroles. ACS Omega 2020, 5, 9023-9030. 